\title{
Physical Exercise is Associated with Glycemic Control among Women with Gestational Diabetes Mellitus: Findings from a Prospective Cohort in Shanghai, China
}

\author{
Ruiping Wang, $\mathbb{D}^{1, *}$ \\ Qiong Yang, ${ }^{2, *}$ Ting Sun, ${ }^{3, *}$ \\ Yan Qiang, ${ }^{1} *$ Xiaopan $\mathrm{Li}^{4}{ }^{4}$ \\ Huan $\mathrm{Li}^{3}{ }^{3}$ Yue Tang, ${ }^{3}$ \\ Liang Yang, ${ }^{5}$ Jie Sun, ${ }^{5}$ Bin $\mathrm{Li}^{1}$ \\ 'Clinical Research \& Innovation \\ Transformation Center, Shanghai Skin \\ Diseases Hospital Affiliated to Tongii \\ University, Shanghai, People's Republic of \\ China; ${ }^{2}$ Office of Public Health, Songjiang \\ Fang Song Community Health Service \\ Center, Shanghai, People's Republic of \\ China; ${ }^{3}$ Obstetrics and Gynecology \\ Department, Songjiang Maternal and Child \\ Health-Care Hospital, Shanghai, People's \\ Republic of China; ${ }^{4}$ Department of Non- \\ Communicable Disease Control and \\ Prevention, Pudong District Center for \\ Diseases Control and Prevention, Shanghai, \\ People's Republic of China; ${ }^{5}$ Department of \\ Women Health, Jing'an Institute of Maternal \\ and Child Health-Care, Shanghai, People's \\ Republic of China
}

*These authors contributed equally to this work

Correspondence: Ruiping Wang Clinical Research \& Innovation

Transformation Center, Shanghai Skin Diseases Hospital Affiliated to Tongji University, I 278 Baode Road, Jing'an District, Shanghai, 200443, People's

Republic of China

Fax +86-2I-36803000

Emailw1983090I@I26.com

Bin $\mathrm{Li}$

Clinical Research \& Innovation

Transformation Center, Shanghai Skin

Diseases Hospital Affiliated to Tongji

University, 1278 Baode Road, Jing'an

District, Shanghai, 200443, People's

Republic of China

Email18930568I29@I26.com
Objective: Physical exercise during pregnancy is beneficial to women with gestational diabetes mellitus (GDM), but evidence on the association between physical exercise and glycemic control among women with GDM is limited in China. We conducted this study to understand the total exercise times, the percentage of abnormal plasma glucose (PG), and to explore if longer physical exercise is positively associated with a lower percentage of abnormal PG among GDM women.

Methods: During 2019 and 2020, we established a prospective cohort with 1,050 GDM women recruited. GDM was confirmed by a diagnostic $75 \mathrm{~g}$ OGTT, and plasma glucose in over 10 hours overnight fasting and 2-hour after breakfast was implemented during a routine antenatal checkup. Information for demographic features and physical exercises among GDM women were collected by questionnaire interviews, and abnormal PG percentage was calculated as abnormal PG times divided by total PG test times.

Results: Among 1,050 GDM women, the percentage of exercise times $<150$ minutes/week, $<30$ minutes/day and $<60$ minutes/day was $17.33 \%, 26.57 \%$, and $54.10 \%$, respectively. The median percentage of abnormal PG was $40 \%$ (IQR=20-70\%). GDM women with less exercise had a higher abnormal PG percentage $\left(y=0.0049 x^{2}-1.20 x+88.96\right)$, ORs for women with exercise $<150$ minutes/week were 3.78 (95\% CI=1.33-8.25), 6.97 (3.45-14.07), and 6.39 (3.61-11.33) compared with $\geq 150$ minutes/week, and ORs for women with exercise $<60$ minutes/day were 4.62 (2.71-8.14), 3.58 (2.60-4.93), and 7.28 (4.31-12.30) compared with $\geq 60$ minutes/day in groups divided by quartiles of $\mathrm{P}_{25}, \mathrm{P}_{50}$ and $\mathrm{P}_{75}$, respectively.

Conclusion: This study indicated high physical exercise times and abnormal PG percentage among women with GDM in Shanghai, China. GDM women with more exercise times had a lower percentage of abnormal PG, especially when exercise times were $\geq 60$ minutes/day, and supplementary treatments should be provided for women with over $70 \%$ abnormal plasma glucose.

Keywords: physical exercise, gestational diabetes mellitus, prospective cohort, association, glycemic control, abnormal plasma glucose

\section{Introduction}

Gestational diabetes mellitus (GDM), defined as any carbohydrate intolerance first recognized during pregnancy, is one of the most common medical conditions and associated with increased risk of adverse perinatal outcomes, both for mother and infant. $^{1-4}$ The prevalence of GDM ranges from $2-32 \%$ around the world, 
and 18.4 million live births are affected by GDM worldwide. ${ }^{5,6}$ In China, the prevalence of GDM has recently increased from $14.7 \%$ to $20.9 \%$, which represents an epidemic proportion. ${ }^{2,7}$ In recent years, lifestyle, imbalanced diet, and a growing number of women with advanced maternal age achieving second pregnancy due to the 'two-child policy in China' may increase the incidence of GDM, which has become a serious burden on public health in China. ${ }^{5}$

The successful management of GDM involving tight glycemic control, ${ }^{8}$ and achieving optimal glycemic control reduces the risk of premature rupture of membranes, preeclampsia, fetal macrosomia, preterm birth, cesarean delivery, ${ }^{7,9}$ and diabetes following delivery as well. ${ }^{10}$ Although both balanced diet and physical exercise are recommended widely to stabilize glucose level in pregnancy, physical exercise is more acceptable than diet suggestion, due to limited nutrition intake being against the traditional perception that pregnancy is a state requiring extra nutrition and care. ${ }^{11}$ The updated physical activity guidelines from The American College of Obstetricians and Gynecologists (ACOG) and Canadian Society for Exercise Physiology (CSEP) recommend at least 150 minutes of moderate intensity physical activity each week for pregnant women without contraindications to achieve meaningful health benefits, ${ }^{12,13}$ but with weak recommendations for GDM women due to low quality evidence. ${ }^{12}$ Padayachee and Coomber ${ }^{14}$ drafted the first guideline on physical exercise specifically for GDM women, which recommends 30-60 minutes of daily moderate intensity exercise at a frequency of three times per week during pregnancy to curb elevated plasma glucose. The moderate intensity exercise is referred to as requiring a normal physical effort that make pregnant women breathe slightly harder and their heart beat a little faster, which can lower glucose levels in women with GDM. $^{11,12,14}$

There has been a controversy about physical exercise in pregnancy, ${ }^{15}$ especially in China due to its traditional perceptions, where pregnancy is treated as a special state that requires extra rest and recuperation by Chinese women, so physical exercise such as riding a bicycle, soft gymnastics, oxygen dance, swimming, and even housework is unacceptable for the majority of women in China. For reasons of exercise controversy and antenatal taboos, around $80 \%$ of pregnant women worldwide are physically inactive, especially in the last trimester of pregnancy. ${ }^{11,15,16}$ In recent years, growing evidence in western countries has demonstrated that physical exercise during pregnancy is beneficial to women with GDM, and could lower the glucose level and reduce the risk of adverse perinatal outcome, ${ }^{1-4,11}$ but evidence on the association of physical exercise during pregnancy and glycemic control among women with GDM is still limited in China.

In this paper, we implemented a descriptive analysis based on a cohort of GDM women in Shanghai, China. We aim to understand the total physical exercise times, as well as the percentage of abnormal plasma glucose (PG) during 27-40 gestation weeks among women with GDM, and to explore if longer exercise times are positively associated with a lower percentage of abnormal PG among GDM women.

\section{Methods}

\section{Study Design and Participants}

During 2019 and 2020, we established a prospective cohort of women with GDM in Songjiang District of Shanghai. The purpose of the GDM women cohort was to explore the influence of physical exercise on adverse perinatal outcomes, the glycemic control during pregnancy, and the incidence rate of type 2 diabetes after the delivery. As reported by Zhang and $\mathrm{Chen}^{17}$ in 2018 , the incidence rate of preterm birth among GDM women with physical exercise $\geq 150$ minutes/week was $10 \%$, we assumed that GDM women with physical exercise $<150$ minutes/week had 2-fold higher preterm birth incidence than those with physical exercise $\geq 150$ minutes/week. In this study, considering the inspection level $(\alpha=0.01)$, and the test power $(\beta=0.2)$, at least 834 GDM would be required by applying PASS 15.0 for sample size calculation, and 1050 GDM women were finally recruited in this study. Eligible pregnant women were recruited in Songjiang Maternal and Children's Health-care Hospital during their prenatal care visit in early pregnancy. Inclusion criteria were: 1) aged 18-45 years; 2) resident living in Songjiang with no plan for migration in the following 2 years; 3) with gestation weeks of 24-28; 4) singleton pregnancy; 5) without preexisting health conditions such as diabetes, hypertension, cancers, ischemic heart diseases; 6) confirmed GDM by a diagnostic $75 \mathrm{~g}$ OGTT ( 0 - $\mathrm{h}$ (fasting) $\geq 5.10 \mathrm{mmol} / \mathrm{L}$, 1-h plasma glucose $\geq 10.00 \mathrm{mmol} / \mathrm{L}$, and 2-h plasma glucose $\geq 8.50 \mathrm{mmol} / \mathrm{L}$ ); and 7) being able to read and sign the informed consent form. The participant recruitment initiated in August 2019 and ended in August 2020. The ethics approval was authorized by Songjiang Maternal and Children's Health-care Hospital Institution Review Board 
(IRB\#-2019-12-003), an informed consent paper was signed by each GDM women before the questionnaire interview, and information that could identify individual participants during or after data collection could not be accessed by authors. This study was conducted following the Declaration of Helsinki, and registered in the Chinese Clinical Trial Registry.

\section{Data Collection}

The questionnaire for data collection includes four parts. Part A covered five questions of demographic information (age, education, occupation, residency status, and individual monthly income). Part B covered 18 questions of the pregnancy and childbirth history, routine antenatal checkup information, the body height and weight before pregnancy, 75g OGTT in 24-28 gestation week, and morning plasma glucose (PG) in over 10 hours overnight fasting state as well as 2 hour after a standard breakfast during routine antenatal checkup in gestational week 27-28, week 29-30, week 31-32, week 33-34, week 35-36, week 37-38, week 39-40, etc. Part C covered 10 questions of newborn delivery information (gestational week, mode of delivery, gender and birthweight of baby, postpartum hemorrhage, etc). Part D covered 20 types of physical exercise in pregnancy (walking, house cleaning, stationary riding, jogging, swimming, climbing stairs, Tai Chi, soft gymnastic, yoga, oxygen dance, etc), information of the frequency and duration for each physical exercise with moderate intensity during gestation week $27-40$ on average before delivery was recorded.

In this study, information for Parts $\mathrm{A}, \mathrm{B}$, and $\mathrm{C}$ was extracted directly from the delivery records and antenatal checkup forms stored in the hospital, and information for Part D was collected through face-to-face interviews by nurses in the ward after delivery.

\section{Definition and Co-Variate Calculation}

In this study, GDM was confirmed by a diagnostic $75 \mathrm{~g}$ OGTT at the gestational week of 24-28 when any one of the following values was met or exceeded: fasting plasma glucose $(0 \mathrm{~h}) \geq 5.10 \mathrm{mmol} / \mathrm{L}, 1-\mathrm{h}$ plasma glucose $\geq 10.00$ $\mathrm{mmol} / \mathrm{L}$, and 2 -h plasma glucose $\geq 8.50 \mathrm{mmol} / \mathrm{L}^{2}$. We defined an abnormal PG as the morning $\mathrm{PG} \geq 5.10 \mathrm{mmol} /$ $\mathrm{L}$ in over 10 hours overnight fasting or (and) $\geq 8.5 \mathrm{mmol} / \mathrm{L}$ in 2-h after a standard breakfast in each routine antenatal checkup after the confirmation of GDM. ${ }^{2,18}$ The glycemic control during pregnancy was evaluated by the percentage of abnormal PG, which was calculated as times of abnormal PG test divided by the total times of PG test, then we classified GDM women into different groups according to the percentage of abnormal PG by quartile value of $\mathrm{P}_{25}(<20 \%$ and $\geq 20 \%), \mathrm{P}_{50}(<40 \%$ and $\geq 40 \%)$, and $\mathrm{P}_{75}(<70 \%$ and $\geq 70 \%)$. In this study, we defined good glycemic control as $<20 \%$ of abnormal PG percentage among all capillary glucose measurements.

Physical exercise with moderate intensity was assessed by the total daily exercise times as well as the total weekly exercise times. First, each physical exercise times was calculated by monthly exercise frequency multiplied with duration of each exercise on average and then divided by 30 days, then we combined the 20 types of physical exercise times to provide the total daily exercise times for each participant, which was multiplied by 7 days to provide the total weekly exercise times as well. For example, a woman with GDM reported two types of moderate intensity physical exercise (walking and oxygen dancing) during gestation weeks 27-40, the frequency and duration were 30 times/month and 20 minutes/time on average for walking, 10 times/month and 15 minutes/time on average for oxygen dancing, so the total daily exercise times was 25 minutes $[(30 * 20+10 * 15) / 30]$, and the total monthly exercise time was 175 minutes (25 minutes*7 days) for this GDM women. We then classified GDM women according to the total daily exercise times into groups of " $<150$ minutes/week" and " $\geq 150$ minutes/week", 12,13 " $<30$ minutes/day" and " $\geq 30$ minutes/day", and " $<60$ minutes/ day" and " $\geq 60$ minutes/day". 14 The " $<30$ minutes/day" group was included in the " $<60$ minutes/day".

In this study, BMI before pregnancy was classified as $<18.5,18.5-24.9,25-29.9$, and $\geq 30[7$, 9]. Weight gain $(\mathrm{kg})$ in gestation was calculated as pre-birth body weight minus pre-pregnancy body weight. The age of GDM women was categorized into four groups (18-25, 26-30, 31-35, and 36-45). Education of GDM women was recorded as completed years of schooling and classified into three categories of 6-9 years (primary or junior high school), 10-12 years (senior high school), and $>12$ years (college and above). Individual monthly income (RMB) was classified into four groups $(<3,000$ '3,000-5,000, 5,001-10,000, and >10,000).

\section{Data Analysis}

In this study, we performed data analysis by SAS software (version 9.4). We described the data by using frequency counts and proportions (percentage) for qualitative variables, mean and standard deviation or median and 
interquartile range (IQR) for quantitative variables. We applied the Chi-square test to examine the percentage differences between physical exercises $<150$ minutes/ week and $\geq 150$ minutes/week, $<30$ minutes/day and $\geq 30$ minutes/day, as well as $<60$ minutes/day and $\geq 60$ minutes/ day among GDM women with different demographic characteristics, we also applied Chi-square test to explore the percentage difference of abnormal PG classified by different quartile $\left(\mathrm{P}_{25}, \mathrm{P}_{50}\right.$, and $\left.\mathrm{P}_{75}\right)$ among GDM women with different demographic characteristics. The non-parametric rank-sum test was used to compare the difference between GDM women with $<150$ minutes/week and $\geq 150$ minutes/ week, $<30$ minutes/day and $\geq 30$ minutes/day, as well as $<60$ minutes/day and $\geq 60$ minutes/day in gestation history, weight gain in gestation, types of physical exercise, and total daily exercise times. Chi-square test for trend was applied to explore the association between the percentage of abnormal PG and gestation weeks. Binomial regression was used to show the dose-response relationship between total daily physical exercise and the percentage of abnormal PG. We applied logistic regression to calculate the odds ratios (OR) and $95 \%$ confidence interval $(95 \% \mathrm{CI})$ to explore the association between physical exercise times and percentage of abnormal PG among different groups of GDM women classified by quartile values of $\mathrm{P}_{25}, \mathrm{P}_{50}$, and $\mathrm{P}_{75}$, with the adjustment of potential confounders. The potential confounders adjusted in logistic regression were identified by using the directed acyclic graphs (DAGs) method. ${ }^{19,20}$ Figures were produced to described the detailed information for the association between total exercise times and percentage of abnormal PG within different groups, as well as the association between the percentage of abnormal PG and total exercise times among GDM women in different gestation weeks. In this study, a $p$-value of less than 0.05 (two-tailed) was considered as statistically significant.

\section{Results}

In this study, 1,050 GDM women included 344 local residents $(32.76 \%)$, the age ranged from $18-45$ with an average age of $30.53 \pm 3.95$ years old; $59.71 \%$ of GDM women had an education of college and above $(>12$ years), and the majority of GDM women had a monthly income over 5,000 RMB (802, 76.38\%). Of the GDM women, $26.00 \%$ were overweight or obese before pregnancy, and $36.76 \%$ of them had a balanced diet with doctors' suggestion after the GDM confirmation (Table 1).

\section{Physical Exercise during Pregnancy among GDM Women}

Among 1050 GDM women, the total daily exercise times ranged from 5-145 minutes, with a median value of 55 $(\mathrm{IQR}=30-70)$ minutes. The percentage of exercise times $<130$ minutes per week among women with GDM was $17.33 \%$ ( $95 \% \mathrm{CI}=15.09-19.76 \%$ ), The percentage of GDM women was $36.57 \%$ (23.92-29.35\%) for exercise times $<30$ minutes per day, and $54.10 \%$ (51.03-57.14\%) for exercise time $<60$ minutes per day.

Table 1 indicates that GDM women aged 36-45 years $(24.82 \%)$ had a higher percentage of exercise time $<150$ minutes/week than women aged 18-25 years (7.81\%) and women aged 26-30 years (13.48\%). GDM women with BMI value of 25-29.9 had a higher percentage of exercise times $<150$ minutes/week (22.41\%) than women with BMI values $<18.5(4.55 \%), 18.5-24.9(16.78 \%)$, and $\geq 30(12.20 \%)$, the differences were statistically significant $(P<0.05)$.

Table 1 demonstrates that elder GDM women had a higher percentage of daily exercise times $<30$ minutes (34.31\% for GDM women aged $36-45$ year). The percentage of daily exercise times $<30$ minutes among GDM women with primary or junior high education (31.05\%) was higher than GDM women with the education of senior high or college and above $(27.45 \%$ and $24.72 \%)$. GDM women with lower monthly income $(<3,000 \mathrm{RMB})$ or higher BMI value ( $\geq 25$ for overweight or obesity), and with a balanced diet had a higher percentage of daily exercise times $<30$ minutes $(32.65 \%, 36.26 \%$, and $30.57 \%$, respectively), the differences were statistically significant $(P<0.05)$.

The percentage of daily exercise times $<60$ minutes among GDM women with primary or junior high education $(62.56 \%)$ was higher than GDM women with the education of senior high or college and above $(55.39 \%$ and $50.72 \%$ ). GDM women with monthly income over 10,000 RMB had a lower percentage of daily exercise time $<60$ minutes $(46.40 \%$ ), and GDM women with a higher BMI value ( $\geq 25$ for overweight or obesity) had a higher percentage of daily exercise times $<60$ minutes $(65.57 \%)$, the differences were statistically significant $(P<0.05)$ (Table 1).

\section{Abnormal PG Test Times among GDM Women}

In this study, the percentage of abnormal PG among GDM women ranged from $0-100 \%$, with a median value of $40 \%$ 
Table I The Demographic Feature and Moderate-Intensity Exercise Condition during Pregnancy among Women with Gestational Diabetes Mellitus (GDM) in a Rural Region of Shanghai, China

\begin{tabular}{|c|c|c|c|c|c|c|c|}
\hline \multirow[t]{2}{*}{ Variables } & \multirow{2}{*}{$\begin{array}{r}\text { GDM } \\
\text { Women } \\
(n=1,050)\end{array}$} & \multicolumn{2}{|c|}{$\begin{array}{r}\text { Women with Exercise }<30 \\
\text { Minutes/Day }\end{array}$} & \multicolumn{2}{|c|}{$\begin{array}{r}\text { Women with Exercise }<60 \\
\text { Minutes/Day }\end{array}$} & \multicolumn{2}{|c|}{$\begin{array}{l}\text { Women with Exercise } \\
<150 \text { Minutes /Week }\end{array}$} \\
\hline & & Yes $(n=279)$ & No $(n=77 I)$ & Yes $(n=568)$ & No $(n=482)$ & Yes $(n=\mid 82)$ & No $(n=868)$ \\
\hline \multicolumn{8}{|l|}{ Age $(\text { years) })^{\dagger \S}, \mathrm{n}(\%)$} \\
\hline $18-25$ & $128(12.19)$ & 27 (21.09) & $101(78.91)$ & $86(67.19)$ & $42(32.8 I)$ & $10(7.81)$ & $118(92.19)$ \\
\hline $26-30$ & $408(38.86)$ & $93(22.79)$ & $315(77.21)$ & $209(51.23)$ & 199 (48.77) & 55 (13.48) & $353(86.52)$ \\
\hline $31-35$ & $377(35.90)$ & II 2 (29.7I) & $265(70.29)$ & $197(52.25)$ & $180(47.75)$ & $83(22.02)$ & $294(77.98)$ \\
\hline $36-45$ & $137(13.05)$ & $47(34.31)$ & $90(65.69)$ & $76(55.47)$ & $61(44.53)$ & $34(24.82)$ & $103(75.18)$ \\
\hline \multicolumn{8}{|l|}{ Education ${ }^{\dagger \ddagger}, \mathrm{n}(\%)$} \\
\hline Primary/Junior High & $219(20.86)$ & $68(31.05)$ & $15 \mid(68.95)$ & I 37 (62.56) & $82(37.44)$ & $4 I(18.72)$ & I78 (8I.28) \\
\hline Senior High & $204(19.43)$ & $56(27.45)$ & $148(72.55)$ & II3 (55.39) & $91(44.61)$ & $36(17.65)$ & $168(82.35)$ \\
\hline College and above & $627(59.7 I)$ & I55 (24.72) & $472(75.28)$ & $318(50.72)$ & $309(49.28)$ & $105(16.75)$ & $522(83.25)$ \\
\hline \multicolumn{8}{|l|}{$\begin{array}{l}\text { Individual monthly income } \\
(\mathrm{RMB})^{\dagger \neq}, \mathrm{n}(\%)\end{array}$} \\
\hline Less than 3,000 & 49 (4.67) & $16(32.65)$ & $33(67.35)$ & $28(57.14)$ & $21(42.86)$ & $8(16.33)$ & $4 \mid(83.67)$ \\
\hline $3,000-5,000$ & $199(18.95)$ & $61(30.65)$ & $138(69.35)$ & $|2|(60.80)$ & $78(39.20)$ & $38(19.10)$ & $161(80.90)$ \\
\hline $5,001-10,000$ & $552(52.57)$ & $148(26.81)$ & $404(73.19)$ & $303(54.89)$ & $249(45.11)$ & $100(18.12)$ & $452(81.88)$ \\
\hline Over 10,000 & $250(23.8 I)$ & $54(21.60)$ & $196(78.40)$ & $116(46.40)$ & $134(53.60)$ & $36(14.40)$ & $214(85.60)$ \\
\hline \multicolumn{8}{|l|}{ Residency status, n (\%) } \\
\hline Local resident & $344(32.76)$ & $96(27.91)$ & 248 (72.09) & 191 (55.52) & $153(44.48)$ & $63(18.31)$ & 281 (8I.69) \\
\hline Non-local resident & $706(67.24)$ & $183(25.92)$ & $523(74.08)$ & $377(53.40)$ & $329(46.60)$ & $119(16.86)$ & $587(83.14)$ \\
\hline \multicolumn{8}{|l|}{$\begin{array}{l}\text { BMI before pregnancy }{ }^{\dagger \ddagger \S} \text {, } \\
\text { n (\%) }\end{array}$} \\
\hline $\begin{array}{l}<18.5 \text { (lower body } \\
\text { weight) }\end{array}$ & $44(4.19)$ & $7(15.91)$ & 37 (84.09) & $25(56.82)$ & $19(43.18)$ & $2(4.55)$ & $42(95.45)$ \\
\hline $\begin{array}{l}\text { I8.5-24.9 (normal body } \\
\text { weight) }\end{array}$ & $733(69.81)$ & $173(23.60)$ & $560(76.40)$ & $364(49.66)$ & $369(50.34)$ & $123(16.78)$ & $610(83.22)$ \\
\hline 25-29.9 (overweight) & $232(22.10)$ & $85(36.64)$ & $147(63.36)$ & I53 (65.95) & 79 (34.05) & $52(22.4 I)$ & $180(77.59)$ \\
\hline$\geq 30$ (obesity) & $4 \mathrm{I}(3.90)$ & $14(34.15)$ & $27(65.85)$ & $26(63.4 I)$ & I5 (36.59) & $5(12.20)$ & $36(87.80)$ \\
\hline \multicolumn{8}{|l|}{$\begin{array}{l}\text { Balanced diet with doctor's } \\
\text { suggestion }{ }^{\dagger}, \mathrm{n}(\%)\end{array}$} \\
\hline Yes & $386(36.76)$ & II 18 (30.57) & $268(69.43)$ & $216(55.96)$ & $170(44.04)$ & 77 (19.95) & $309(80.05)$ \\
\hline No & $664(63.24)$ & I6I (24.25) & $503(75.75)$ & $352(53.01)$ & $312(46.99)$ & $105(15.8 \mathrm{I})$ & $559(84.19)$ \\
\hline $\begin{array}{l}\text { Times of gestation }(\mathrm{G}) \text {, } \\
\text { Median (IQR) }\end{array}$ & $2(I-3)$ & $2(I-3)$ & $2(I-3)$ & $2(I-3)$ & $2(I-3)$ & $2(I-3)$ & $2(I-3)$ \\
\hline $\begin{array}{l}\text { Times of Production }(\mathrm{P}) \text {, } \\
\text { Median (IQR) }\end{array}$ & $2(I-2)$ & $2(I-2)$ & $2(I-2)$ & $2(I-2)$ & $2(I-2)$ & $2(I-2)$ & $2(I-2)$ \\
\hline $\begin{array}{l}\text { Times of abortion (A), } \\
\text { Median (IQR) }\end{array}$ & $0(0-1)$ & I $(0-I)$ & $0(0-1)$ & $0(0-1)$ & $I(0-I)$ & $0.50(0-1)$ & $0(0-1)$ \\
\hline Weight gain in gestation & 9.40 & 9 & 9.70 & 9.30 & 9.55 & 8.40 & 9.70 \\
\hline$(\mathrm{kg})+\S$, Median (IQR) & $(7.00-12.30)$ & $(6.20-11.50)$ & $(7.20-12.60)$ & $(7.00-12.10)$ & $(6.90-12.70)$ & $(5.60-11.20)$ & $(7.20-12.50)$ \\
\hline $\begin{array}{l}\text { Types of exercise engaged } \\
\text { in, Median (IQR) }\end{array}$ & $3(2-4)$ & $3(I-5)$ & $3(2-4)$ & $3(2-4)$ & $4(2-5)$ & $4(2-5)$ & $3(2-4)$ \\
\hline
\end{tabular}

(Continued) 
Table I (Continued).

\begin{tabular}{|l|r|r|r|r|r|r|r|}
\hline Variables & $\begin{array}{r}\text { GDM } \\
\text { Women } \\
(\mathbf{n = 1 , 0 5 0 )}\end{array}$ & $\begin{array}{r}\text { Women with Exercise <30 } \\
\text { Minutes/Day }\end{array}$ & $\begin{array}{r}\text { Women with Exercise <60 } \\
\text { Minutes/Day }\end{array}$ & \multicolumn{2}{|}{$\begin{array}{r}\text { Women with Exercise } \\
<150 \text { Minutes /Week }\end{array}$} \\
\cline { 3 - 7 } & Yes (n=279) & No (n=77I) & Yes (n=568) & No (n=482) & Yes (n=182) & No (n=868) \\
\hline $\begin{array}{l}\text { Daily exercise times } \\
\text { (minutes) } \dagger \ddagger \S, \text { Median (IQR) }\end{array}$ & $55(30-70)$ & $20(15-30)$ & $60(50-80)$ & $\begin{array}{r}34.50 \\
(20.00-45.00)\end{array}$ & $\begin{array}{r}73.50 \\
(60.00-80.00)\end{array}$ & $15(10-20)$ & $60(45-75)$ \\
\hline
\end{tabular}

Notes: ${ }^{\dagger}$ The differences between group on proportion of daily moderate intensity exercise time less than 30 minutes among women with GDM was statistically significant $(P<0.05) .{ }^{\ddagger}$ The differences between group on proportion of daily exercise time less than 60 minutes among women with GDM was statistically significant $(P<0.05) .{ }^{\S}$ The differences between group on proportion of weekly moderate intensity exercise time less than 150 minutes among women with $G D M$ was statistically significant $(P<0.05)$.

$(\mathrm{IQR}=20-70 \%)$. We then classified GDM women into three different groups according to the percentage of abnormal $\mathrm{PG}$ by quartile value of $\mathrm{P}_{25}(<20 \%$ and $\geq 20 \%)$, $\mathrm{P}_{50}(<40 \%$ and $\geq 40 \%)$, and $\mathrm{P}_{75} \quad(<70 \%$ and $\geq 70 \%)$ (Table 2).

Figure 1 indicates that GDM women with less physical exercise times had a higher percentage of abnormal PG test $\left(\mathrm{y}=0.0049 \mathrm{x}^{2}-1.20 \mathrm{x}+88.96, \mathrm{R}^{2}=0.46, P<0.001\right)$. In all three groups of GDM women divided by abnormal PG percentage with quartile of $\mathrm{P}_{25}, \mathrm{P}_{50}$, and $\mathrm{P}_{75}$, GDM women with exercise times $<30$ minutes/day, $<60$ minutes/day, and $<150$ minutes/week had a higher proportion of abnormal PG percentage, the proportions were $96.06 \%, 90.67 \%$, and $100.00 \%$ for abnormal PG percentage $\geq 20 \%$, the proportions were $83.51 \%, 68.49 \%$, and $92.31 \%$ for abnormal PG percentage $\geq 40 \%$, as well as $50.18 \%, 37.15 \%$, and $64.29 \%$ for abnormal PG percentage $\geq 70 \%$, respectively, the differences were statistically significant $(P<0.05)$. GDM women with the education of college and above had a lower proportion of abnormal PG percentage (71.77\%, 41.95\%, and $19.78 \%$ for quartile of $\mathrm{P}_{25}, \mathrm{P}_{50}$, and $\mathrm{P}_{75}$, respectively) than women with primary school, junior high or senior high, the differences were statistically significant $(P<0.05)$. The percentage of abnormal PG was higher among GDM women with BMI of 25-29.9 $\left(81.90 \%, 59.50 \%\right.$, and $30.60 \%$ for quartile of $\mathrm{P}_{25}, \mathrm{P}_{50}$, and $\mathrm{P}_{75}$, respectively) and $\mathrm{BMI}$ of $\geq 30(92.68 \%, 70.73 \%$, and $31.71 \%$ for quartile of $\mathrm{P}_{25}, \mathrm{P}_{50}$, and $\mathrm{P}_{75}$, respectively) than women with BMI of 18.5-24.9, or BMI less than 18.5, the differences were statistically significant $(P<0.05)$ (Table 2).

For GDM women divided by the cut-off value of $\mathrm{P}_{50}$ ( $<40 \%$ and $\geq 40 \%$ ), the proportion of abnormal PG percentage was higher among GDM women aged 18-25 years $(52.34 \%)$ or $36-45$ years $(56.20 \%)$, and GDM women with monthly income over 10,000 RMB had a lower proportion of abnormal PG percentage (38.40\%), the differences were statistically significant $(P<0.05)$ (Table 2$)$.

Figure 2 indicates that the percentage of abnormal PG decreased gradually with the gestational weeks among GDM women $\left(\chi^{2}\right.$ for trend between 8 gestational weeks and percentage of abnormal PG among all GDM women was $37.30, P<0.001)$. In each gestational week after the confirmation of GDM, women with exercise time $<150$ minutes/week (Figure 2A), $<30$ minutes/day (Figure 2B), and $<60$ minutes/day (Figure 2C) had a higher percentage of abnormal $\mathrm{PG}$ than women with $\geq 150$ minutes/week, $\geq 30$ minutes/day, and $\geq 60$ minutes/ day, correspondingly. The differences were all statistically significant $(P<0.05)$.

\section{Association between Daily Exercise Times and Abnormal PG Test among GDM Women}

In this study, GDM women with exercise time $<150$ minutes/week had higher prevalence of abnormal PG, even after the adjustment of potential confounders, the OR was $3.78(95 \% \mathrm{CI}=1.33-8.25)$ in groups divided by quartile of $\mathrm{P}_{25}, 6.97$ (3.45-14.07) in groups divided by quartile $\mathrm{P}_{50}$, and 6.39 (3.61-11.33) in groups divided by quartile of $\mathrm{P}_{75}$, respectively. Similarly, GDM women with daily exercise time $<30$ minutes had a higher prevalence of abnormal PG, the OR was 3.53 (1.64-7.67) in groups divided by quartile of $\mathrm{P}_{25}, 1.56$ (1.04-2.55) in groups divided by quartile $\mathrm{P}_{50}$, and 2.86 (1.50-3.66) in groups divided by quartile of $\mathrm{P}_{75}$, respectively. GDM women with daily exercise time $<60$ minutes also had a higher prevalence of abnormal PG with the adjustment of potential confounders, the OR was 4.62 (2.71-8.14) in groups divided by quartile of $\mathrm{P}_{25}, 3.58$ (2.60-4.93) in groups divided by quartile of $\mathrm{P}_{50}$, and 7.28 (4.31-12.30) in groups divided by quartile of $\mathrm{P}_{75}$, respectively (Table 3 ). 
Table 2 The Percentage of Abnormal PG (Plasma Glucose) Test Times with Different Cutoff Values among GDM Women in a Rural Area of Shanghai, China

\begin{tabular}{|c|c|c|c|c|c|c|}
\hline \multirow[t]{2}{*}{ Variables } & \multicolumn{2}{|c|}{$\begin{array}{c}\text { Percentage of Abnormal PG } \\
\text { Test Times with Cutoff } \\
\text { Value of } \mathbf{P}_{25}\end{array}$} & \multicolumn{2}{|c|}{$\begin{array}{c}\text { Percentage of Abnormal PG } \\
\text { Test Times with Cutoff } \\
\text { Value of } \mathbf{P}_{50}\end{array}$} & \multicolumn{2}{|c|}{$\begin{array}{c}\text { Percentage of Abnormal PG } \\
\text { Test Times with Cutoff } \\
\text { Value of } P_{75}\end{array}$} \\
\hline & $\geq \mathbf{2 0} \%$, n (\%) & $<20 \%, n(\%)$ & $\geq \mathbf{4 0 \%}$, n (\%) & $<40 \%, n(\%)$ & $\geq 70 \%$, n (\%) & $<70 \%, \mathrm{n}(\%)$ \\
\hline \multicolumn{7}{|l|}{ Exercise time $<30$ minutes/day ${ }^{1 \neq \dagger}$} \\
\hline Yes $(n=279)$ & $268(96.06)$ & II (3.94) & $233(83.5 \mathrm{I})$ & $46(16.49)$ & $140(50.18)$ & $139(49.82)$ \\
\hline No $(n=77 I)$ & $531(68.87)$ & $240(31.13)$ & $273(35.4 I)$ & $498(64.59)$ & $91(11.80)$ & $680(88.20)$ \\
\hline \multicolumn{7}{|l|}{ Exercise time $<60$ minutes/day ${ }^{1 \neq \dagger}$} \\
\hline Yes $(n=568)$ & $515(90.67)$ & $53(9.33)$ & 389 (68.49) & $179(31.5 \mathrm{I})$ & $211(37.15)$ & $357(62.85)$ \\
\hline No $(n=482)$ & $284(58.92)$ & $198(4 \mid .08)$ & II 7 (24.27) & $365(75.73)$ & $20(4.15)$ & $462(95.85)$ \\
\hline \multicolumn{7}{|l|}{ Exercise time $<150$ minutes/week ${ }^{1 \neq \dagger}$} \\
\hline Yes $(n=182)$ & $182(100.00)$ & $0(0.00)$ & $168(92.31)$ & $14(7.69)$ & $117(64.29)$ & $65(35.7 I)$ \\
\hline No $(n=868)$ & $617(71.08)$ & $25 I(28.92)$ & $338(38.94)$ & $530(61.04)$ & $114(13.13)$ & $754(86.87)$ \\
\hline \multicolumn{7}{|l|}{ Age (years) ${ }^{\ddagger}$} \\
\hline $18-25$ & I0I (78.9I) & 27 (21.09) & $67(52.34)$ & $61(47.66)$ & $25(19.53)$ & $103(80.47)$ \\
\hline $26-30$ & $298(73.04)$ & $110(26.96)$ & $177(43.38)$ & $231(56.62)$ & $83(20.34)$ & $325(79.66)$ \\
\hline $31-35$ & $291(77.19)$ & $86(22.8 I)$ & I85 (49.07) & $192(50.93)$ & $87(23.08)$ & $290(76.92)$ \\
\hline $36-45$ & $109(79.56)$ & $28(20.44)$ & $77(56.20)$ & $60(43.80)$ & $36(26.28)$ & $101(73.72)$ \\
\hline \multicolumn{7}{|l|}{ Education ${ }^{1 \neq \dagger}$} \\
\hline Primary/Junior High & $180(82.19)$ & $39(\mid 7.8 I)$ & I25 (57.08) & $94(42.92)$ & $59(26.94)$ & $160(73.06)$ \\
\hline Senior High & $169(82.84)$ & $35(17.16)$ & II 8 (57.84) & $86(42.16)$ & $48(23.53)$ & $156(76.47)$ \\
\hline College and above & $450(71.77)$ & $177(28.23)$ & $263(41.95)$ & $364(58.05)$ & $124(19.78)$ & $503(80.22)$ \\
\hline \multicolumn{7}{|l|}{ Individual monthly income (RMB) ${ }^{\ddagger}$} \\
\hline Less than 3,000 & $40(81.63)$ & $9(18.37)$ & $29(59.18)$ & $20(40.82)$ & $8(16.33)$ & $4 \mathrm{I}(83.67)$ \\
\hline $3,000-5,000$ & $160(80.40)$ & $39(19.60)$ & $103(51.76)$ & $96(48.24)$ & $48(24.12)$ & I5I (75.88) \\
\hline $5,00 I-10,000$ & $416(75.36)$ & $136(24.64)$ & $278(50.36)$ & $274(49.64)$ & |3| (23.73) & $421(76.27)$ \\
\hline Over 10,000 & $183(73.20)$ & $67(26.80)$ & $96(38.40)$ & I54 (6I.60) & $44(17.60)$ & $206(82.40)$ \\
\hline \multicolumn{7}{|l|}{ BMI before pregnancy ${ }^{\mathrm{t}+\dagger}$} \\
\hline <I8.5 (lower body weight) & $30(68.18)$ & $14(31.82)$ & $18(40.91)$ & $26(59.09)$ & $5(11.36)$ & $39(88.64)$ \\
\hline I8.5-24.9 (normal body weight) & $54 I(73.8 I)$ & $192(26.19)$ & $322(43.93)$ & $4 I I(56.07)$ & $142(19.37)$ & $591(80.63)$ \\
\hline 25-29.9 (overweight) & $190(81.90)$ & $42(18.10)$ & I $37(59.50)$ & $95(40.95)$ & $71(30.60)$ & I6I (69.40) \\
\hline$\geq 30$ (obesity) & $38(92.68)$ & $3(7.32)$ & $29(70.73)$ & $12(29.27)$ & $13(3|.7|)$ & $28(68.29)$ \\
\hline \multicolumn{7}{|l|}{ Residency status } \\
\hline Local resident & 270 (78.49) & $74(21.5 I)$ & $164(47.67)$ & $180(52.33)$ & $71(20.64)$ & $273(79.36)$ \\
\hline Non-local resident & $529(74.93)$ & $177(25.07)$ & $342(48.44)$ & $364(51.56)$ & $160(22.66)$ & $546(77.34)$ \\
\hline \multicolumn{7}{|l|}{ Balanced diet with doctor's suggestion } \\
\hline Yes & $288(74.6 I)$ & 98 (25.39) & I85 (47.93) & $201(52.07)$ & $86(22.28)$ & $300(77.72)$ \\
\hline No & $5 \mathrm{II}(76.96)$ & I53 (23.04) & 321 (48.34) & $343(51.66)$ & $145(21.84)$ & $519(78.16)$ \\
\hline
\end{tabular}

Notes: ${ }^{\mathrm{E}}$ The percentage of abnormal PG test times with $\mathrm{P}_{25}$ cutoff value among different groups of women with GDM was statistically significant $(P<0.05)$. ${ }^{\ddagger}$ The percentage of abnormal $P G$ test times with $P_{50}$ cutoff value among different groups of women with GDM was statistically significant $(P<0.05){ }^{\dagger}{ }^{\dagger}$ The percentage of abnormal $P G$ test times with $P_{75}$ cutoff value among different groups of women with GDM was statistically significant $(P<0.05)$.

Figure 3 demonstrates that the percentage of abnormal PG was statistically higher in GDM women with exercise time $<150$ minutes/week than women with $\geq 150$ minutes/ week, and higher in GDM women with daily exercise times $<30$ minutes than $\geq 30$ minutes, as well as higher in daily exercise times $<60$ minutes than $\geq 60$ minutes, in all groups classified by interquartile $\mathrm{P}_{0}$ to $\mathrm{P}_{25}(0-20 \%), \mathrm{P}_{25}$ to $\mathrm{P}_{50}(21-40 \%)$ and $\mathrm{P}_{50}$ to $\mathrm{P}_{75}(41-70 \%)$, the differences 


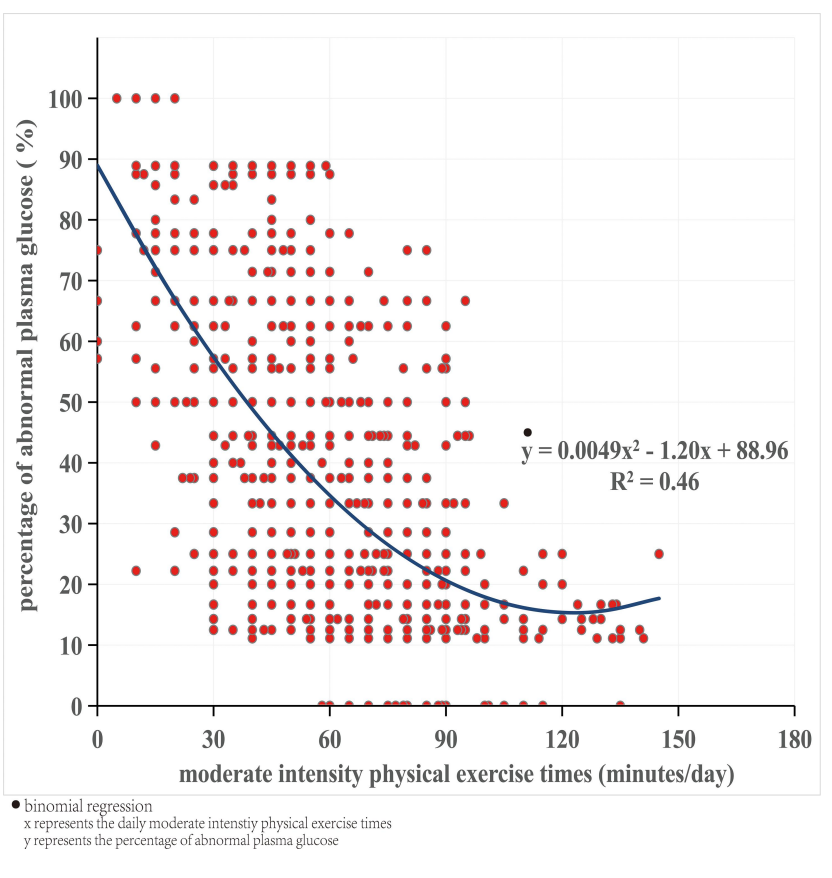

Figure I The association between moderate intensity physical exercise times and the percentage of abnormal plasma glucose among GDM women, with the analysis of binomial regression.

were statistically significant $(P<0.05)$, but not in groups classified as $\mathrm{P}_{75}$ to $\mathrm{P}_{100}(71-100 \%)$ (Figure 3 ).

\section{Discussion}

GDM is one of the most common complications of pregnancy, the hyperglycemia status of GDM lays health hazards both for mother and infant, ${ }^{21}$ and women with a history of GDM have elevated cardiovascular disease risk factors including triglyceride levels, lower HDL, high blood pressure, and 7-fold risk of type 2 diabetes as well. $^{22,23}$ So glycemic control by physical exercise and balanced diet is critical for women with GDM, which can reduce the capillary glucose level and adverse perinatal outcomes. ${ }^{11,15,23}$ In this study, we identified that moderate intensity physical exercise times were associated with the percentage of abnormal plasma glucose (PG), GDM women with more physical exercise times had a lower percentage of abnormal PG. Moreover, GDM women with weekly exercise time $<150$ minutes had a 3.78-6.97-fold higher abnormal PG percentage than those with weekly exercise time $\geq 150$ minutes, and GDM women with daily exercise time $<30$ minutes had a 1.56-3.53-fold higher abnormal PG percentage than those with daily exercise time $\geq 30$ minutes, and GDM women with daily exercise time $<60$ minutes had a $3.58-$ 7.28-fold higher abnormal PG percentage than those with daily exercise time $\geq 60$ minutes, these findings were consistent with previous studies. ${ }^{24}$ The association between more physical exercise times and lower percentage of abnormal plasma glucose among GDM women might be explained by the fact that physical exercise may actively affect insulin resistance in patients with GDM. ${ }^{24}$ The insulin resistance can increase energy supply for lipid oxidation, promote glucose phosphorylation in muscle cells, and transformblood sugar to myosin to make glucose more stable so as to maintain the balance between glucose and insulin secretion. ${ }^{25}$

Pregnancy is a unique period that can affect a woman's health and her fetus as well. Although guidelines recommend women without contraindications engage in prenatal physical activities, ${ }^{13,26}$ less than $15 \%$ of pregnant women perform the minimum amount of exercise recommended by global pregnancy exercise and diabetes guidelines, which is 150 minutes of moderate intensity exercise per week. ${ }^{12,27,28}$ In this study, the median value of total daily exercise times among women with GDM in Shanghai was 55 minutes, and over $80 \%$ of GDM women performed at least 150 minutes of moderate intensity exercise per week, which was higher than findings among women with GDM in the United States (575 Metabolic Equivalent Task (MET) min/ week), ${ }^{24}$ Vietnam (12.6 Metabolic Equivalent Task [MET] hours/week) and India (15 MET hours/week). ${ }^{23,29}$ In China, pregnancy is treated as a special state that requires extra attention and recuperation by Chinese women. When pregnant women were diagnosed with GDM in gestation week 24-28, the obstetrician would prescribe them with more times of routine antenatal checkup, and provide detailed information on physical exercise for plasma glucose control. Moreover, most of the Chinese pregnant women lived with their parents who would supervise and accompany them to perform physical exercise according to the suggestion from the obstetricians, this might be the explanation for the high percentage of Chinese women with GDM who perform 150 minutes physical exercise per week.

In this study, we observed a high percentage of abnormal PG among GDM women, the percentage of abnormal PG ranged from $39.65-47.81 \%$ in gestation week $27-40$. According to the standard of glycemic control in GEM (GDM's Effects on Moms) in the United States, which defined glycemic control as $\geq 80 \%$ of all capillary glucose measurements meeting the targets recommended across Kaiser Permanente Northern California, ${ }^{24,30}$ the percentage 


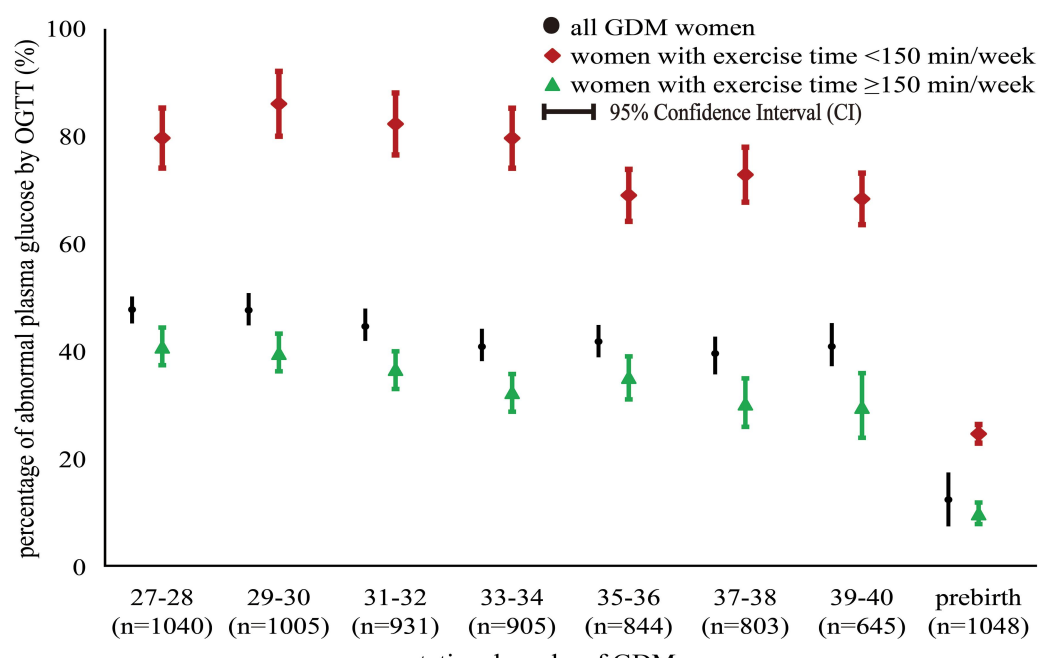

part A

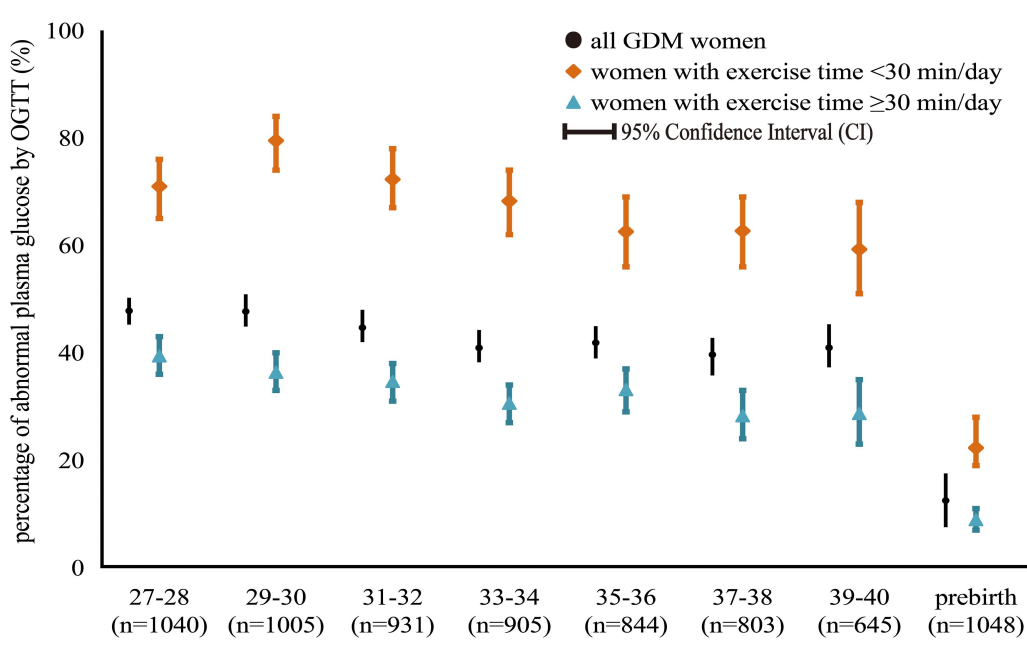

part B

gestational weeks of GDM woman

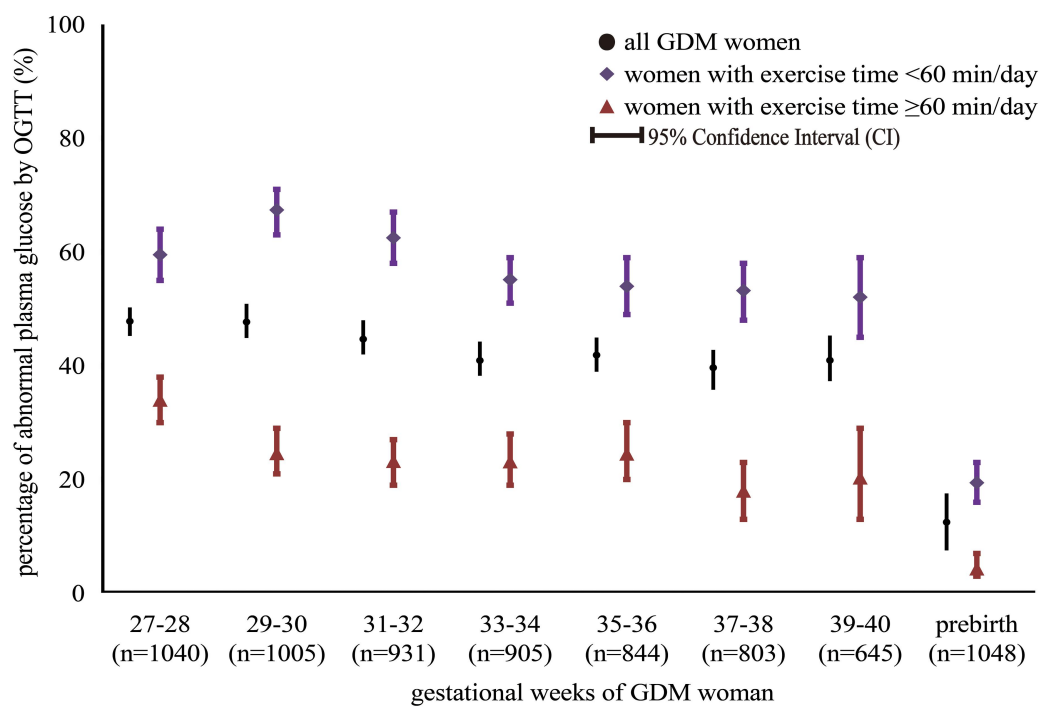

part $\mathbf{C}$

Figure 2 The percentage of abnormal plasma glucose in gestational week 27-40 after the confirmation of GDM, among GDM women with physical exercise $<150$ minutes/ week and $\geq 150$ minutes/week (A), $<30$ minutes/day and $\geq 30$ minutes/day (B), as well as $<60$ minutes/day and $\geq 60$ minutes/day (C). 
Table 3 The Association between Exercise Times and Abnormal Percentage of PG Test Times with Different Cutoff Values among GDM Women in a Rural Area of Shanghai, China

\begin{tabular}{|c|c|c|c|c|c|c|}
\hline \multirow[t]{2}{*}{ Variables } & \multicolumn{2}{|c|}{ LR (a) } & \multicolumn{2}{|c|}{ LR (b) } & \multicolumn{2}{|c|}{$\operatorname{LR}(c)$} \\
\hline & OR & $95 \% \mathrm{Cl}$ & OR & $95 \% \mathrm{Cl}$ & OR & $95 \% \mathrm{Cl}$ \\
\hline \multicolumn{7}{|l|}{ Exercise time $<30$ minutes/day } \\
\hline Yes $(n=279)$ & 3.53 & I.64-7.67 & 1.56 & $1.04-2.55$ & 2.86 & $1.50-3.66$ \\
\hline No $(n=77 I)$ & 1.00 & - & 1.00 & - & 1.00 & - \\
\hline \multicolumn{7}{|l|}{ Exercise time $<60$ minutes/day } \\
\hline Yes $(n=568)$ & 4.62 & $2.7 I-8.14$ & 3.58 & $2.60-4.93$ & 7.28 & $4.31-12.30$ \\
\hline No $(n=482)$ & 1.00 & - & 1.00 & - & 1.00 & - \\
\hline \multicolumn{7}{|l|}{ Exercise time $<150$ minutes/week } \\
\hline Yes $(n=\mid 82)$ & 3.78 & $1.33-8.25$ & 6.97 & $3.45-14.07$ & 6.39 & $3.6 I-11.33$ \\
\hline No $(n=868)$ & 1.00 & - & 1.00 & - & 1.00 & \\
\hline \multicolumn{7}{|l|}{ Education } \\
\hline Primary/Junior High & $\mathrm{I} .47$ & $0.97-2.24$ & 1.64 & $|.07-2.5|$ & 1.24 & $0.81-1.89$ \\
\hline Senior High & 1.38 & $1.22-2.88$ & 2.07 & $1.39-3.07$ & 1.18 & $0.76-1.85$ \\
\hline College and above & 1.00 & - & 1.00 & - & 1.00 & - \\
\hline \multicolumn{7}{|l|}{ BMI before pregnancy } \\
\hline <18.5 (lower body weight) & 1.00 & - & 1.00 & - & 1.00 & - \\
\hline 18.5-24.9 (normal body weight) & 1.58 & $0.76-3.26$ & 0.99 & $0.50-1.96$ & 1.55 & $0.56-4.30$ \\
\hline 25-29.9 (overweight) & 1.87 & $0.85-4.13$ & 1.46 & $0.70-3.02$ & 2.31 & $0.8 I-6.59$ \\
\hline$\geq 30$ (obesity) & 5.86 & $1.43-24.10$ & 2.86 & $1.05-7.80$ & 3.25 & $0.93-11.37$ \\
\hline \multicolumn{7}{|l|}{ Individual monthly income (RMB) } \\
\hline Less than 3,000 & - & - & 1.00 & - & - & - \\
\hline $3,000-5,000$ & - & - & 0.54 & $0.26-1.14$ & - & - \\
\hline $5,001-10,000$ & - & - & 0.76 & $0.37-1.54$ & - & - \\
\hline Over 10,000 & - & - & 0.59 & $0.28-1.26$ & - & - \\
\hline
\end{tabular}

Notes: LR(a): Multi-variate logistic regression for percentage of abnormal PG test times with $P_{25}$ cutoff values among GDM women, with the adjustment of education and BMI before pregnancy (covariates adjusted during the logistic regression were selected by Directed Acyclic Graph (DAG) method). LR(b): Multi-variate logistic regression for percentage of abnormal PG test times with $P_{50}$ cutoff values among GDM women, with the adjustment of education, BMI before pregnancy and individual monthly income (covariates adjusted during the logistic regression were selected by Directed Acyclic Graph (DAG) method). LR(c): Multivariate logistic regression for percentage of abnormal PG test times with $\mathrm{P}_{75}$ cutoff values among GDM women, with the adjustment of education and BMI before pregnancy (covariates adjusted during the logistic regression were selected by Directed Acyclic Graph (DAG) method).

of glycemic control was only $23.90 \%$ among women with GDM in Shanghai, which was lower than the findings in GEM. The lower glycemic control percentage and higher physical exercise over 150 minutes per week among GDM women in Shanghai indicated that physical exercise recommendations for pregnant women without contraindication in CSEP and ACOG might be not proper for women with GDM. ${ }^{12,13}$ As stated in the 2019 Canadian guideline for physical activity throughout pregnancy, at least 150 minutes moderate intensity physical exercise per week was a weak recommendation with low quality evidence, because the net benefit between GDM women who were physically active and those who were not was small. ${ }^{12}$ In this study, we identified that GDM women with daily exercise time $\geq 60$ minutes (about $\geq 420$ minutes/week) had a lower percentage of abnormal PG, which ranged from $18.03 \%$ to $34.02 \%$ with an average of $21.55 \%$, and almost $90 \%$ of them met the targets of glycemic control, so GDM women might need more moderate intensity physical exercise to achieve the goal of glycemic control.

In GDM women with abnormal PG percentage $\geq 70 \%$, differences of abnormal PG percentage was not statistically significant between GDM women with weekly exercise time $<150$ minutes and $\geq 150$ minutes, and between GDM women with daily exercise time $<30$ minutes and $\geq 30$ minutes, even between GDM women with daily exercise time $<60$ minutes and $\geq 60$ minutes. This indicated that moderate intensity physical exercise alone even with over 


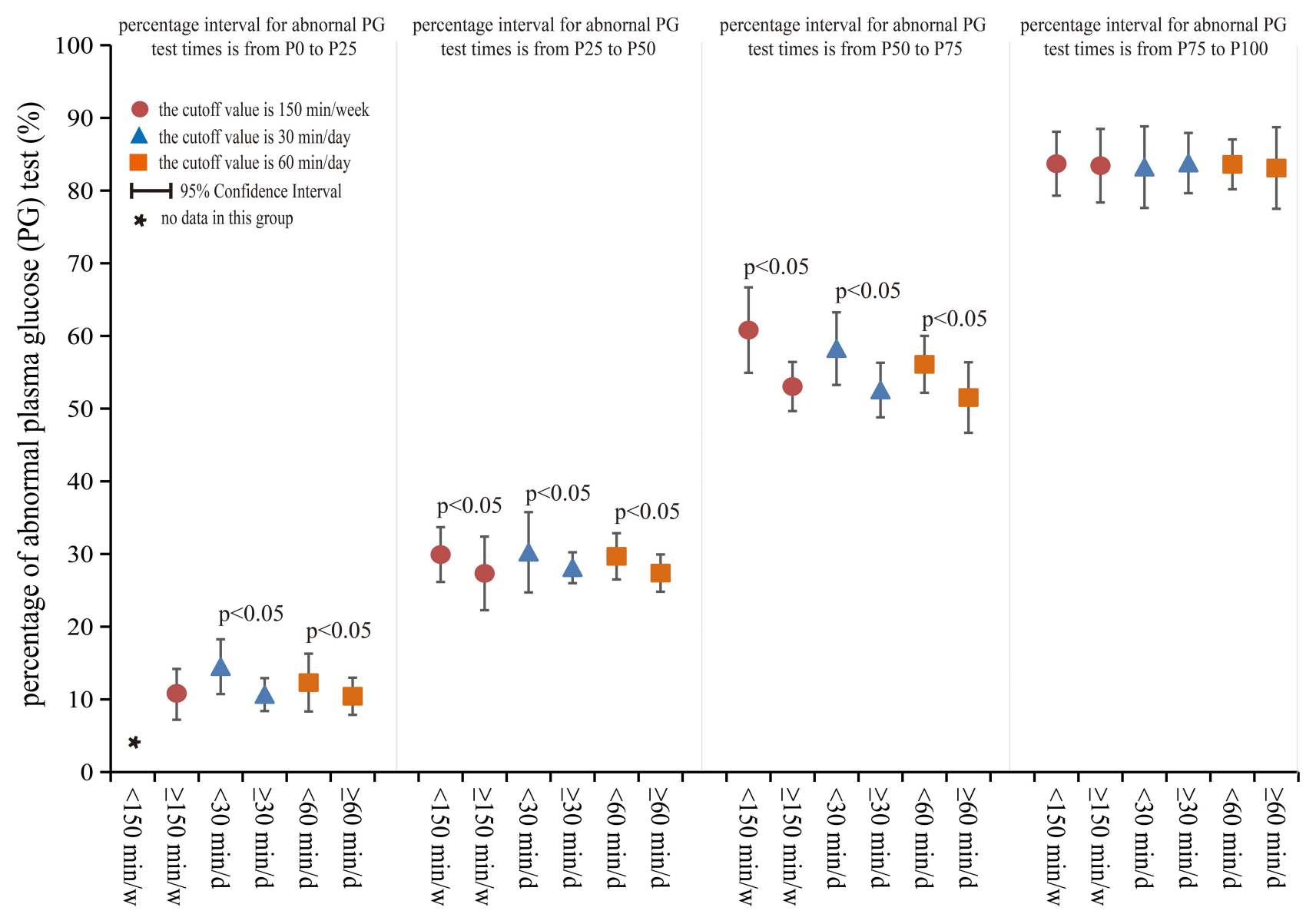

moderate intensity physical exercise among GDM women (d for day, w for week)

Figure 3 The difference of abnormal plasma glucose percentage among GDM women between physical exercise $<150$ minutes/week and $\geq 150$ minutes/week, $<30$ minutes/ day and $\geq 30$ minutes/day, as well as $<60$ minutes/day and $\geq 60$ minutes/day, in four groups with abnormal PG percentage classified by interquartiles of $P_{25}$, $P_{50}$, and $P_{75}$.

60 minutes per day (480 minutes/week) might not be enough for good glycemic control among GDM women with over $70 \%$ abnormal plasma glucose. So supplemented measures such as insulin and glucose control drugs should be provided for GDM women with high abnormal plasma glucose, and obstetrician, gynecologist and other obstetric care provider should evaluate their medical and obstetric complications carefully before making recommendations and adjusted as medically indicated. ${ }^{13,26}$

This study is the first attempt to estimate the association of the total moderate intensity physical exercise times and the percentage of abnormal PG (glycemic control) among women with GDM in Shanghai, China. A strength of this study is the GDM women cohort with a large population size. We included 1,050 women with GDM, accounting for around 70\% of total GDM women in a year in Songjiang District, Shanghai. In this study, information for pregnancy and childbirth history, morning plasma glucose in fasting state as well as 2-hour after breakfast during routine antenatal checkup were extracted directly from the delivery records and routine antenatal checkup forms in hospital, which contributed to a relatively lower recall bias. Meanwhile, we used directed acyclic graphs (DAGs) to identify potential confounders and then adjusted them in the logistic regression analysis, ${ }^{19,20}$ which ensures a relatively unbiased association between physical exercise times and the percentage of abnormal PG, which is another strength of this study.

Our study also has limitations. First, physical exercise was evaluated by a self-designed form covering 20 types of physical exercise, the finding of moderate physical exercise times in this study has limited direct comparability with MET (hour/week or minutes/week) produced by The Pregnancy Physical Activity Questionnaire (PPAQ) in previous studies. Therefore, 
future studies with the incorporation of a compendium of physical activities could improve the in-depth data analysis and the comparability with previous studies. ${ }^{31}$ Second, information of physical exercise among GDM women was self-reported, which might result in overreporting, and equal proportion misclassification of women in quartile from inactive to active level due to the prospective cohort study design, leading to a potential risk of underestimating the odds ratios. ${ }^{32}$ Third, a detailed diet assessment of women with GDM was not performed in this study, the combined effort of diet and physical exercise could not be investigated. So the incorporation of some improvements should be considered in further follow-up studies.

\section{Conclusions}

This study indicated high physical exercise times as well as a high abnormal PG percentage among women with GDM in Shanghai, China. GDM women with more physical exercise times had a lower percentage of abnormal PG, especially among GDM women with exercise times $\geq 60$ minutes per day, and supplementary treatments should be provided for GDM women with over $70 \%$ abnormal plasma glucose.

\section{Abbreviations}

GDM, gestational diabetes mellitus; ACOG, American College of Obstetricians and Gynecologists; PG, plasma glucose; OGTT, oral glucose tolerance test; OR, odds ratios; CI, confidence interval; DAGs, directed acyclic graphs; IQR, interquartile range; BMI, body mass index; MET, metabolic equivalent task; GEM, GDM's effects on moms; PPAQ, pregnancy physical activity questionnaire.

\section{Data Sharing Statement}

Data for this study can be made available upon request from the corresponding author. The request should state the title and aim of the research for which the data are being requested.

\section{Ethics Approval and Consent to Participate}

The ethics approval was approved by Songjiang Maternal and Childcare Hospital Institution Review Board (IRB\#2019-12-003). An informed consent paper was signed by each participant before the questionnaire interview.

\section{Consent for Publication}

Not applicable

\section{Acknowledgment}

We thank Professor Michael Engelau (Center for Diseases Control and Prevention, US) and klossi Chen from University of California, Los Angeles for giving suggestions and comments for this manuscript.

\section{Author Contributions}

All authors in this paper made substantial contributions to conception and design, acquisition of data, or analysis and interpretation of data; took part in drafting the article or revising it critically for important intellectual content; agreed to submit to the current journal; gave final approval of the version to be published; and agree to be accountable for all aspects of the work.

\section{Funding}

This study was supported by grants from the Research Program of Shanghai Sports Bureau (20Q001), Shanghai Shenkang Hospital Development Center Management Research Program (2020SKMR-32) and the National Key R \& D Program of China (2018YFC1705300). The funder had no role in study design, data collection and analysis, decision for publication, or preparation of the manuscript.

\section{Disclosure}

The authors report no competing interests in this work.

\section{References}

1. Metzger BE, Buchanan TA, De LA, et al. Summary and recommendations of the fifth international workshop-conference on gestational diabetes. Diabetes Care. 2007;30(Suppl 2):S251-60. doi:10.2337/ dc07-s225

2. Zhu W, Yang HX, Wei YM, et al. Evaluation of the value of fasting plasma glucose in the first prenatal visit to diagnose gestational diabetes mellitus in China. Diabetes Care. 2013;36(3):586-5900. doi: $10.2337 / \mathrm{dc} 12-1157$

3. Guariguata L, Linnenkamp U, Beagley J, et al. Global estimates of the prevalence of hyperglycaemia in pregnancy. Diabetes Res Clin Pract. 2014;103(2):176-185. doi:10.1016/j.diabres.2013.11.003

4. Koning SH, Hoogenberg K, Lutgers HL, et al. Gestational Diabetes Mellitus: current knowledge and unmet needs. J Diabetes. 2016;8 (6):770-781. doi:10.1111/1753-0407.12422

5. Xie YP, Zhao HF, Liu CH, et al. A meta analysis of the effects of resistance training on blood sugar and pregnancy outcomes. Midwifery. 2020;91:102839. doi:10.1016/j.midw.2020.102839

6. Cho NH, Shaw JE, Karuranga S, et al. IDF Diabetes Atlas: global estimates of diabetes prevalence for 2017 and projections for 2045 . Diabetes Res Clin Pract. 2018;138:271-281. doi:10.1016/j. diabres.2018.02.023 
7. Gou BH, Guan HM, Bi YX, et al. Gestational diabetes: weight gain during pregnancy and its relationship to pregnancy outcomes. Chin Med J. 2019;132(2):154-160. doi:10.1097/CM9.0000000000000036

8. Iren B, Milada VS, Anne FJ, et al. Effect of the pregnant+ smartphone application in women with gestational diabetes mellitus: a randomized controlled trial i Norway. BMJ Open. 2019;9: e030884. doi:10.1136/bmjopen-2019-030884

9. Landon MB, Spong CY, Thom E, et al. A multicenter, randomized trial of treatment for mild gestational diabetes. $N$ Engl J Med. 2009;361(14):1339-1348. doi:10.1056/NEJMoa0902430

10. Baptiste Roberts K, Barone BB, Gary TL, et al. Risk factors for type 2 diabetes among women with gestational diabetes: a systematic review. Am J Med. 2009;122(3):207-214. doi:10.1016/j. amjmed.2008.09.034

11. Lee DT, Ngai IS, Ng MM, et al. Antenatal taboos among Chinese women in Hong Kong. Midwifery. 2009;25:104-113. doi:10.1016/j. midw.2007.01.008

12. Michelle FM, Margie HD, Stephanie MR, et al. 2019 Canadian guideline for physical activity throughout pregnancy. $\mathrm{Br} J$ Sports Med. 2018;52:1339-1346. doi:10.1136/bjsports-2018-100056

13. ACOG Committee Opinion No. 804: physical activity and exercise during pregnancy and the postpartum period: ACOG Committee Opinion No. 804. Obstet Gynecol. 2020;135(4):e178-e188. doi:10.1097/AOG.0000000000003772

14. Padayachee C, Coombes JS. Exercise guidelines for gestational diabetes mellitus. World J Diabetes. 2015;6:1033-1034. doi:10.4239/ wjd.v6.i8.1033

15. Song $\mathrm{C}$, Li J, Leng J, et al. Lifestyle intervention can reduce the risk of gestational diabetes: a meta-analysis of randomized controlled trials. Obes Rev. 2016;17:960-969. doi:10.1111/obr.12442

16. Sinclair I, St-Pierre M, Elgbeili G, et al. Psychosocial stress, sedentary behavior, and physical activity during pregnancy among Canadian women: relationship in a diverse cohort and a nationwide sample. Int J Environ Res Public Health. 2019;16:5150. doi:10.3390/ ijerph16245150

17. Zhang JF, Chen MK. Effect of exercise and diet intervention on pregnant outcomes pregnant women with gestational diabetes mellitus. Med J Wuhan Univ. 2018;39(6):970-973.

18. Metzger BE, Gabbe SG, Persson B, et al; International Association of Diabetes and Pregnancy Study Groups Consensus Panel. International Association of Diabetes and Pregnancy Study Groups recommendations on the diagnosis and classification of hyperglycemia in pregnancy. Diabetes Care. 2010;33:676-682.

19. Peter WGT, Elenor JM, Kellyn FA, et al. Use of directed acyclic graphs (DAGs) to identify confounders in applied health research: review and recommendations. Int J Epidemiol. 2020. doi:10.1093/ije/ dyaa213.
20. Hardt J, Brendler C, Greiser KH, et al. Directed acyclic graphs (DAGs)-basic concepts and application of an approach for causal analyses in epidemiology. Gesundheitswesen. 2011;73(12):888-892. doi:10.1055/s-0031-1291192

21. Metzger B, Gabbe S, Persson B, et al. International association of diabetes and pregnancy study groups recommendations on the diagnosis and classification of hyperglycemia in pregnancy. Diabetes Care. 2010;33:676-682. doi:10.2337/dc10-0719

22. Bellamy L, Casas J, Hingorani A, et al. Type 2 diabetes mellitus after gestational diabetes: a systematic review and meta-analysis. Lancet. 2009;373:1773-1779. doi:10.1016/S0140-6736(09)60731-5

23. Nguyen CL, Pham NM, Lee AH, et al. Physical activity during pregnancy is associated with a lower prevalence of gestational diabetes mellitus in Vietnam. Acta Diabetol. 2018;55(9):955-962. doi: 10.1007/s00592-018-1174-3

24. Ehrlich SF, Sternfeld B, Krefman AE, et al. Moderate and vigorous intensity exercise during pregnancy and gestational weight gain in women with gestational diabetes. Matern Child Health J. 2016;20 (6):1247-1257. doi:10.1007/s10995-016-1926-z

25. Pan BX, Luo ML. Research progress of resistance training therapy and nursing in diabetes. Nurs Pract Res. 2016;13(20):27-29.

26. U.S. Department of Health and Human Services. Physical Activity Guidelines for Americans. 2nd ed. Washington DC: DHHS; 2018. Available from: https://health.gov/paguidelines/second-edition/.

27. Evenson KR, Barakat R, Brown WJ, et al. Guidelines for physical activity during pregnancy: comparisons from around the world. Am J Lifestyle Med. 2014;8:102-121. doi:10.1177/1559827613498204

28. Evenson KR, Wen F. Prevalence and correlates of objectively measured physical activity and sedentary behavior among US pregnant women. Prev Med. 2011;53(1-2):39-43. doi:10.1016/j. ypmed.2011.04.014

29. Surabhi M, Surekha K. Effect of physical activity during pregnancy on gestational diabetes mellitus. Indian $J$ Endocr Metab. 2018;22:661-671. doi:10.4103/ijem.IJEM 618 17

30. American Diabetes Association. Management of diabetes in pregnancy. Diabetes Care. 2017;40(Suppl 1):S114-S119. doi: $10.2337 / \mathrm{dc} 17-\mathrm{S} 016$

31. Ainsworth BE, Haskell WL, Herrmann SD, et al. 2011 compendium of physical activities: a second update of codes and MET values. Med Sci Sports Exerc. 2011;43(8):1575-1581. doi:10.1249/ MSS.0b013e31821ece12

32. Pekkanen J, Sunyer J, Chinn S. Nondifferential disease misclassification may bias incidence risk ratios away from the null. $J$ Clin Epidemiol. 2006;59(3):281-289. doi:10.1016/j.jclinepi.2005.07.013

Diabetes, Metabolic Syndrome and Obesity: Targets and Therapy

Dovepress

Publish your work in this journal

Diabetes, Metabolic Syndrome and Obesity: Targets and Therapy is an international, peer-reviewed open-access journal committed to the rapid publication of the latest laboratory and clinical findings in the fields of diabetes, metabolic syndrome and obesity research. Original research, review, case reports, hypothesis formation, expert opinion and commentaries are all considered for publication. The manuscript management system is completely online and includes a very quick and fair peer-review system, which is all easy to use. Visit http://www.dovepress.com/testimonials.php to read real quotes from published authors. 